\title{
THE IMPORTANCE AND RELEVANCE OF INCORPORATING ETHICS AS PART OF ENGINEERING EDUCATION - A POSITION PAPER
}

\author{
Anders FOLKMAN, Varg FOLKMAN and Rein Terje THORSTENSEN \\ University of Agder, Norway
}

\begin{abstract}
Most classical university educations include ethics as an integral part of the curriculum requirements. Education for both medicine and law have strict legal requirements where ethics are compulsory subjects. Both professions follow up with further requirements for continuing education in ethics. At least in Norway, parallel requirements are not present for engineering education, despite the existence of a "National framework for engineering educations". The need for ethical behaviour amongst stakeholders in society is timelier than ever. Engineers and designers are societal stakeholders. There is a need for discussion amongst educators on how to provide young professionals with the moral ballast and motivation to act as the future professional exemplars, needed in society.

This article investigates alternative strategies for incorporating ethical awareness and training in education, based on a discussion of published research. The driving force is the continuously on-going quality assurance of our own engineering education programme. In the lack of general requirements for the implementation of ethics in engineering education, the conclusions from this investigation will be implemented in the continuous revision of the education at our own university; as a minimum through the teaching practice of the involved authors. It is our intention to follow up by evaluating effects over time, through surveys and further assessments. Thus, through the discussion partly referred to in this paper, we clarify and state our position in this important discussion. The conclusion is meant for acting as a summary for further debate.
\end{abstract}

Keywords: Ethics as part of engineering education, incorporating ethical issues in teaching, strategies for ethics in engineering education programmes.

\section{INTRODUCTION}

Engineers make ethical decisions; business behaviour, advising clients, execution of works and environmental issues. Making the "right choice" often conflicts with economic interests. However, consciousness in valuations increase the quality of decisions and might improve the value of both individuals and corporations in the longer run.

Engineers are often in powerful positions, able to influence society substantially - also as role models for others. Hence, ethics should be considered a prominent part of all engineering education, as important as any other part of the education programme.

All people have a sense of right and wrong. It is crucial to nurture and develop that sense to educate young professionals equipped with ethical ballast, making them able to identify situations where their moral judgments are called for - and to (re-)act responsibly. Numbers might give of an aura of objectivity, but even within the most number-based fields of science and engineering, philosophers of science, evolutionary psychologists and others have for years been questioning the practitioner's ability to divest their own prior assumptions, limitations and biases from their work.

In "The Structure of Scientific Revolutions" the philosopher of science Thomas Kuhn drew attention to the social and collegial aspect of scientific discovery. The fellow philosopher Paul Feyerabend expanded on this in "Against Method. Outline of an anarchistic theory of knowledge" [1]. Feyerabend and Kuhn in similar 
fashion pointed at the rhetoric involved in scientific work, and how assumptions about conventional wisdom staggered acknowledgement of objective errors.

The phenomenon discussed by Kuhn has since been strengthened by the work of evolutionary cognitive behavioural economists. Behavioural economists like Daniel Kahneman has since Kuhn's days shown how cognitive biases like confirmation bias and groupthink significantly hinder us from fully functioning as rational beings [2]. Similarly, cognitive psychologists like Dan Sperber has suggested that human rationality might be an evolutionary cooperation tool, and hence a flawed instrument for pure, unbiased reasoning [3]. The dichotomy between the seemingly powerful human urge for reason and the flawed ability to reason is denoted "the double enigma" by Mercier and Sperber. Reason primarily helps us persuade and convince each other, rather than to engage in solitary reflection. They suggest that unbiased reasoning has been overruled by evolution. Hence, our apparent tendency to generate and bolster weak arguments while more critically evaluating the reasoning of others is fundamentally a social action. Another urge away from functioning as rational beings - confirmation bias - is our tendency to irrationally search for evidence that confirms rather than falsifies, the hypothesis we have in mind.

It is not obvious how the education programmes should incorporate ethical issues, to nurture and develop awareness and response reflexes. For most traditional university educations, ethics is given as an independent introductory subject. This is not always the case for engineering education, and it might not necessarily be the best strategy. In an earlier article, one of the present authors investigated ethical responsibilities for universities, when relating to industry [4]. A concept for understanding the "University Societal responsibility" (USR) was suggested, parallel to the well-established term "Corporate Societal responsibility" (CSR). The suggested USR model divides universities' societal responsibility into four areas (Figure 1).

\begin{tabular}{|rcccc|}
\hline Discretionary & Ethical & Legal & Main societal mandate: \\
Responsibilities & Responsibilities & Responsibilities & Rnowledge, and distributing it through \\
& & & education, innovation and public debate \\
\hline
\end{tabular}

Figure 1. Suggestion for conceptualizing "University Societal Responsibility" (USR) comprising four areas, including implying relative magnitude amongst those

As that article focuses on the societal role of universities, a distinction is made between "legal responsibilities" (defined by formal regulations) and "ethical responsibilities" (defined by norms for behaviour and activities expected by society's members, without yet have been formalized into regulations). However, when focusing on how ethics should be implemented in engineering education, it might be relevant to cover both areas, both to make students aware of the distinction between formalized regulations and norms, and to nurture the moral responsibility of professional engineers to attend both.

The suggested USR-model also refers to an article by Marrewijk [5], discussing how relationship between the three main actors in society (state, business and civil society) continuously develop through times towards higher degree of overlapping. This is claimed to influence the relative size of each of the four areas in the USR model, making the concepts of ethical and legal responsibilities increase over time. This further emphasizes the urge to incorporate ethics as part of engineering education.

\section{THE ROLE OF ETHICS IN TODAYS ENGINEERING EDUCATION}

Engineers hold powerful positions, and their decisions forms and norms the society. In Norway, there are national requirements for some ethics in education curricula, as law and medicine. Amongst them are not the engineering education curricula. Teaching ethics as a part of the curricula is to secure a certain level of common standards and quality. The requirements for contents on ethics in some curricula are very limited. This is a problem that has been raised several times by engineer related institutions, including the "Norwegian Society of Engineers" (NIF/TEKNA). However, this questioning has never propelled any radical changes. However, these national requirements for curricula open for local adjustments and do not prevent inclusion of ethical topics. 
Most classical university educations include ethics as an integral part of the requirements. Both medicine and law have strict legal requirements, where ethics are compulsory subjects in the educations. In both professions, there are further requirements for continuing education in ethics. For example, practising attorneys must attend 5 hours of ethics every five years to reach their requirement for continuing education. Doctors have corresponding requirements. It is hard to argue against the same integral courses in engineering as engineers hold important positions in society.

\section{DISCUSSING WHEN AND WHERE THE PROFESSIONAL AWARENESS SHOULD BE DEVELOPED}

\subsection{Working life}

Frequently, the mass media forward stories on working life's violation of societal responsibility regarding ethics. Referring to figure 1; when these are violations of legal responsibilities, questions on legal sanctions towards the responsible persons are clamoured. Relevant cases for illustration are frequently revealed, like several cases where even governmental institutions are building clients for construction sites where illegal immigrants are working. In these cases, it is often also revealed that the working conditions for those workers are far beyond legal requirements. However, responsibility is pulverized through unclear instructions and contractual requirements. If any, legal sanctions are directed towards "small fishes" rather than the systems not having the power to prevent these situations to appear.

When the violation of ethical norms regards ethical responsibilities rather than legal ones (again referring to figure 1), revelation seems even harder to obtain, and sanctions seem less accessible. Application examples are everywhere; regarding business behaviour, when advising clients, in the execution of works and in environmental issues, including awareness on fair decisions in bidding processes. Often, making the "right choice" conflicts with economic interests - at least in short terms. Consciousness in relation to valuations has the power to increase the quality of decisions and thus might improve the reputation and value of both individuals and corporations in the longer run.

Why are these situations so often neglected by highly educated and competent personnel, and left to casual revelation by the mass media? It is probably not obtainable to create systems that secure against violations neither towards legal nor ethical responsibilities. However, the question remains why these actions were not revealed at early stages by witnessing personnel guided by ethical ballast. Our special attention goes towards the several layers of engineers being involved in planning and execution of major projects.

Going back to Kahneman [2], cognitive biases like confirmation and groupthink significantly hinder us from fully functioning as rational beings. The authority of group justice might explain the lack of action from personnel that should have competence to react and alert. Sperber even suggested that human rationality might be an evolutionary cooperation tool, and hence a flawed instrument for pure, unbiased reasoning [3]. Individual competence on awareness to discover ethical dilemmas and ballast for executing value judgements is obtainable. However, it requires development through stimulation, nurturing and challenging. An expectation might be that education on these issues should be left to working life, where application examples are everywhere. However, it seems clear that this solution is not sufficient, and that ethical training should be a part of engineering education. Indications are clear that training ethical competence should be a part of continuing education throughout the working life of engineers.

\subsection{Engineering education}

The lack of focus on ethics in engineering education might create a vacuum in the professional engineers' awareness of the fact that they are making value judgements and on consequences of these. Students, like all people, have a sense of right and wrong. It is important to nurture and develop that sense, to educate young professionals equipped with ethical ballast making them able to identify situations where their ethical judgments are called for, and to act in responsible ways.

Making ethics a part of the curriculum seems requested. However, behaving ethically is not necessarily a simple task, and ethical problems are rarely presented in Manichean terms of a simple "right" or "wrong". Evaluating one's own previous work enlightened by history, most people might find that seemingly non- 
controversial choices or decisions made in good faith, in fact, were not that clear cut and turned out to be part of an unfortunate whole.

This is where a substantial education of future engineers and other professionals becomes key, also to handle the seemingly invisible questions posed by modern technology, and those where one's own role seems minor and negligible compared to a monumental whole.

In another article, Thorstensen et al. [6] compare ethical guidelines established by Engineering Societies in three leading countries. Even though originating from highly different societies, these guidelines appear to be harmonic and closely related. Like in most countries, also the Norwegian Engineering societies (NITO/TEKNA) offer corresponding ethical guidelines, intended for professional use.

The guidelines are equipped with educational materials including ethical rules, ethical road maps and guidelines for warning of unethical issues. All materials are available on the organization's home for society members, including students. Hence, all are easily available for facilitation both in industry and at universities. Still, a systematic implementation in engineering education is still not conducted.

\section{STRATEGIES FOR INCORPORATING ETHICS IN ENGINEERING EDUCATION}

Several strategies are available for including ethics in engineering education. Two main alternatives would be either to treat ethics as a separate topic or to integrate ethics in the engineering topics. Herkert [7] discusses the alternatives of doing it as separate courses or integrated into the technical curriculum. He argues that ethics taught as a separate topic is challenging both to economy and organization of the educational programme (due to an already tight schedule) - and even more important: it "can leave the students with the impression that ethics is a sidebar rather than an integral part of their engineering studies". It is our clear perception from teaching practice, that most engineering students are heavily focusing on what they understand as the profession - tending to neglect vaguely adjacent topics. Another reason for preferring to include ethics as an integral part of the technical curriculum is what Mercier and Sperber [3] denote "confirmation bias" - our tendency to irrationally search for evidence that confirms rather than falsifies, the hypothesis we have in mind. This tendency is presumably stronger in areas where students bring hypothesis to the table, as they probably will do concerning areas central to the educational programme they are pursuing. Again, it is in accordance with our experience that working with ethical issues integrated into technical curricula will better challenge the students' preconceptions than handling ethical issues as separate curricula. Hence, they will be more prone to develop personal ethical ballast through integration.

Also, the question of how ethics should be taught might have several answers. A traditional university approach would be to handle the topic from a theoretical origin. However, though probably highly engaging to some groups of students, we doubt this approach to be welcomed by most engineering students. Harris et al. [8] ascertain that "there is widespread agreement that the best way to teach professional ethics is by using cases", without any further discussion. Once again, Mercier and Sperber [3] might help the argumentation, as they claim that "reason primarily helps us persuade and convince each other, rather than to engage in solitary reflection". Understanding this as if the social process of persuading and convincing each other is a driving force for developing reason, might emphasize the pedagogical value of learning ethics by working with cases as advantageous to other pedagogical methods.

The reason why universities should teach ethics is clear; society needs engineers to practice their profession according to ethical norms. More formally, this is argued and modelled in Thorstensen et al. [4], illustrated in Figure 1. The discussion on this model emphasizes the need for developing an understanding for both the codified and the tacit ethical competence when training engineering students for ethical execution of the profession. This competence needs to include an understanding of the time-dependent development of the relativity in this model, as argued by Marrewijk [5] and further discussed in[4]. Ability to execute the engineering profession according to ethical norms requires two things: 1) knowledge of ethical standards and 2) personal moral or ballast. Knowledge of ethical standards can be taught. However, building personal moral or ballast cannot be taught - it requires efforts and involvement. Neither Herkert [7] nor Harris et al. [8] discusses why the students should really involve in in ethical training - not just consider it an additional burden. 
It is widely accepted by practitioners from teaching, that awakening personal involvement amongst the students is a major route to success. Han [9] introduces the term "moral motivation", as a strategy to shift away from earlier moral educational paradigms focusing on rule-based ethics and preventive moral education. In its place, he argues for a eudemonic approach (contrasting to hedonistic happiness), where students are seeking wellbeing through professional excellence. To achieve this moral motivation, Han introduces the necessity of professional exemplar - the role model. By accentuating the educational cases through exemplars having respect in the profession, Han claims, one can prevent students from experiencing the sense of conflict between moral and career values.

Harris et al. [8] also discuss two alternative methods for working with cases to train ethical competence; "drawing the line" and "conflict" or "competing considerations". Both methods might gain more authority, if presented and supervised by professional exemplars, deeply respected for both technical expertise and ethical competence. The model also invites for caretaking of gender issues when composing the team of exemplars. Through this moral modelling method, it seems possible to ignite a moral motivation amongst students and prepare coming engineers for autonomous ethically informed decision-making.

\section{CONCLUSIONS}

Just like for doctors and lawyers, there is a need for ethical training amongst engineers and designers to foster the moral ballast and motivation required for young professionals to act as tomorrows professional exemplars. Training must be integrated into education programmes. The following conclusions are stating our position so far, and is meant for acting as a summary for further debate:

1. Engineers possess vital positions, having the power to norm society and making decisions that are, in fact, value judgements of great importance. Frequent revelations of negative cases from working life's violation of societal responsibilities on ethics (both legal and norms), demonstrates that engineers are not sufficiently competent to handle these situations.

2. Through a discussion on a well-known human tendency towards group thinking and hence biased rationality, we suggest that it is vital to develop the ethical ballast on an individual basis to overcome this compliance to group-justice.

3. Working life seems not to offer the sufficient training arena for ethical competence. Hence, it must be incorporated in education. However, working life offers a variety of educational and relevant cases, and cooperation on this part of the education might also gain a need for continuing education through the career of engineers.

4. Casework seems to be a suitable tool for training awareness and individual ballast on ethical issues, well fitted for methods like "drawing the line" and "conflict" or "competing considerations". However, all of these need the students to possess moral motivation for obtaining relevant dividend.

5. Moral motivation might be nurtured by a eudemonic approach, where students are seeking wellbeing through professional excellence. A model might be the use of professional exemplars; having the educational work presented and supervised by professional exemplars, deeply respected for both technical expertise and ethical competence.

6. Use of professional exemplars might also invite for caretaking of gender issues when composing the team of exemplars, heavily needed in this near uni-gender profession.

\section{REFERENCES}

[1] Feyerabend, P., Against Method. Outline of an anarchistic theory of knowledge. London (Verso) 1975. 1975.

[2] Kahneman, D. and Egan P., Thinking, fast and slow. Vol. 1. 2011: Farrar, Straus and Giroux New York.

[3] Mercier, H. and Sperber D., The enigma of reason. 2017: Harvard University Press.

[4] Thorstensen, R. T., Svennevig P. R., and Larsen I. L., Societal responsibility in engineering education; a case study on R\&DI-cooperation within civil engineering. in Proceedings of the 20th 
International Conference on Engineering and Product Design Education 2018. Dyson School of Engineering, Imperial College, London: The design Society.

[5] van Marrewijk, M., Concepts and definitions of CSR and corporate sustainability: Between agency and communion. Journal of business ethics, 2003. 44: p. 95-105.

[6] Thorstensen, R. T., Folkman A. and Svennevig P. R., Approaching a concept for societal responsibility in engineering education. in DS 95: Proceedings of the 21st International Conference on Engineering and Product Design Education (E\&PDE 2019), University of Strathclyde, Glasgow. 12th-13th September 2019. 2019.

[7] Herkert, J.R.J.E.j.o.e.e., Engineering ethics education in the USA: Content, pedagogy and curriculum. European Journal of Engineering Education, 2000. 25(4): p. 303-313.

[8] Harris Jr, C.E., et al., Engineering ethics: what? why? how? and when? Journal of engineering education, 1996. 85(2): p. 93-96.

[9] Han, H. J. S. and E. Ethics, Virtue ethics, positive psychology, and a new model of science and engineering ethics education. 2015. 21(2): p. 441-460. 